\section{The impact of the surgical mask on the relationship between patient and family nurse in primary care}

\author{
Ana Raquel Braga* and Irene P Carvalho \\ Faculty of Medicine, University of Porto, Rua da Barranha $n^{\circ} 761$ 2nd dto 4460256 Matosinhos, \\ Portugal
}

\section{Abstract}

Objective: In primary care, during treatments, nurses may need to wear surgical masks, namely for control of infection contamination, or to minimize unpleasant odors. The goal of this study is to inspect the effect of nurses wearing the mask on patient perception of the nurse-patient relation.

Methods: A pre-post-test, control-experimental group design was employed with 60 patients treated in family health units. Patients responded to the Patient Satisfaction Questionnaire III (PSQ-III) regarding nurses' communication, interpersonal manner, technical quality, as well regarding general satisfaction with the encounter. An additional question asked both patients and nurses how long they felt that the visit lasted.

Results: Results show that nurses wearing the surgical mask had significantly negative effects in all dimensions of PSQ-III and increased the perceived visit duration among both nurses and patients.

Conclusion: When a previous relationship exists, nurses wearing the surgical mask in primary care in Portugal negatively affects patient satisfaction with both the patient-nurse relation and the nurses' technical quality.

Practice implications: Is important the nurse understand this impact to discuss with the colleagues the best strategy to minimize the negative impact to the patient- family nurse relation and manager this situation in the best way to the patient.

\author{
More Information \\ *Address for Correspondence: \\ Ana Raquel Braga, Faculty of Medicine, \\ University of Porto, Rua da Barranha $n^{\circ} 761$ 2nd \\ dto 4460256 Matosinhos, Portugal, \\ Tel: 00351912853556; \\ Email : anabraga.ag@gmail.com; \\ anabraga.ag.mcc@gmail.com \\ Submitted: January 22, 2021 \\ Approved: February 10, 2021 \\ Published: February 11, 2021
}

How to cite this article: Braga AR, Carvalho IP. The impact of the surgical mask on the relationship between patient and family nurse in primary care. Clin J Nurs Care Pract. 2021; 5: 003-008.

DOI: 10.29328/journal.cjncp.1001030

ORCiD: orcid.org/0000-0001-9587-7304

Copyright: $\odot 2021$ Braga AR, et al. This is an open access article distributed under the Creative Commons Attribution License, which permits unrestricted use, distribution, and reproduction in any medium, provided the original work is properly cited.

Keywords: Family nurse care; Patient satisfaction; Patient-nurse relationship; Surgical mask; Technical quality; Communication; Visit duration

(A) Check for updates

OPEN ACCESS

\section{Introduction}

The use of the surgical mask has well-known benefits for both the patient and the professional regarding the control of infection contamination [1]. However, its use is left to individual criteria, and is passed on from generation to generation of nurses through experiential, intuitive knowledge. Studies are necessary to support the use of the surgical mask $[2,3]$.

Although the surgical mask presents protective advantages that justify its use, the use of the mask in primary healthcare, as in other areas of nursing care, can influence communication and relationship with the patient. Some studies indicate that the use of the mask restrict the perception of words and, consequently, the transmission of information by the professionals to the patients [4-6]. Using the mask can create a physical barrier that makes difficult perceive the words and also the (micro) facial expressions that are important for communication and for the relation, even if it does not prejudice the procedure performed by the nurse $[7,8]$. It can also have a symbolic function of personal distancing that can be appreciated as dutiful professional care or viewed as a limit.

The interpersonal relationship and the professionalism perceived by the patients are fundamental for the nurses' performance and for the individual health gains or of the family, community earnings. The objective of the interaction between the patient and the nurse is to ensure that the patient's needs are identified, and the necessary care is provided, either in the sense of changing behaviors for the acquisition of healthy lifestyles or health recovery [9]. In the primary care the placement of a surgical mask during a treatment, may convey an image of the most distant nurse, possibly even with disgust for the care she gives due to the 
occasional odor from the dressing material and/or wounds. Alternatively, the use of facemask can carry an idea of greater professionalism through the expectations of the patients about the image that a nurse should present when execute a treatment. The family nurse is the first point of contact of the patient with the health care system, as the patient in all life processes follows for a long period of time in which clinical discharge is not assumed. The quality of the relationship is important, namely make the patient feel safe and not compromising their confidence. For example, several studies suggest that breakdown of alliances or perceptions of value judgments induce the patient to disguise or omit clinical and/or family conditions crucial to their biopsychosocial well-being [7-10]. If the use of the surgical mask represents a break in the alliance or transport the idea of judgment regarding the patient or his health problem may compromise clinical practice. In the case of the family nurse, contact with the patient is continued and it is essential to maintain the quality of the relationship over time.

Out of crisis situations, in the ordinary practice of health care, what is the impact of the use of masks by family nurses on patient satisfaction? This study aims to evaluate the effect that the use of surgical mask in primary care has on patient satisfaction regarding: (1) the relation with the nurse and (2) the perception of technical quality of the nurse. This study pretends to close an existing gap regarding the practice of using surgical masks by family nurses. This knowledge can be important in clinical practice, namely sensitizing nurses to the effects of wearing the mask on the patient-nurse relation.

\section{Patient satisfaction with the patient-family nurse relation}

Satisfaction is an individual perception linked to the fulfilment of an expectation or to the satisfaction of a need. Satisfaction occurs when the difference between service provided and expected is positive [11]. Studies shows how longer the time spent in the same unit with the same health professionals, the greater is the satisfaction of the patient. This increases gradually over the years, as well as tolerance for situations that other more recent users find less satisfactory $[12,13]$. On the other hand, in a primary health care study in Hong Kong shows that the interference of the surgical mask was negative in empathy and general patient satisfaction with the appointment, but only in those who already had an established relationship with their family doctor [14].

The perception of technical quality is directly related to the relationship established. For example, there is no satisfactory clinical relationship if the user does not trust the professional's technical knowledge and qualities [15]. Some propose that professional competence includes both knowledge to solve problems and a relational function of effective communication with patients [16]. Nevertheless, it is possible to distinguish technical quality from interpersonal relationship [11,15]. Technical quality refers to aspects such as theoretical knowledge, examination and procedural skills [16], and includes rigor, precision, risks and errors involved in the processes of diagnosis and treatment [17]. In turn, relationship dimensions refer to communication skills [16] and include aspects such as listening, asking questions, providing information and counselling, as well as showing respect, openness and caring attitude towards the patient's ideas, values and concerns. The latter attitudes have been described as "humanistic qualities" and define the professional's interpersonal manner, determining the effect of communication on another person [18].

It is thus possible that the use of the surgical mask has different effects on patient satisfaction with the nurse's technical quality and on patient satisfaction with the relationship with the nurse. For example, research reported that patients' ratings of physicians' communication, but not of physicians' technical quality, was a key predictor of patient satisfaction [19]. The use of the mask might decrease patient satisfaction with the relationship (if, for example, it is perceived as a physical barrier or is associated with personal distancing) and simultaneously increase satisfaction with the nurse's technical quality (if, for example, it is associated with the expectation that the nurse should wear protective mask while performing a certain function) [10].

\section{Methods}

This study was carried out in portuguese family health units (FHU) belonging to the country's Northern Health Regional Administration area (ARSN) from May 2018 to August 2018. Patients in the FHUs and their respective family nurses were invited to participate, receiving information about the study. Those who agreed to participate signed an informed consent. The study was approved by the ARSN Ethics Committee.

\section{Sample}

Our sample is composed of patients with chronic wounds from two health units in Portuguese primary care, and their family nurses participated in this study. The convenience sample is composed with patients with chronic wound who were 18 years of age or older, could read and write in Portuguese, had autopsychic and alopsychic, had a previous relationship with their family nurse for at least 18 months and at the time needed, due to their pathology, at least two consecutive treatments at FHU. The Sample characteristics is described on table 1.

\section{Procedure}

This study was conducted in two consecutive appointments between the same patient-nurse dyad (each patient received two medical treatments in the same week).

The visits had the approximate duration of 13 minutes ( mean $=13.22 ; \mathrm{SD}=3.06)$. The 60 patients were randomly 
Table 1: Sample characteristics.

\begin{tabular}{|c|c|c|c|}
\hline & Total $(n=60)$ & Control group $(n=30)$ & Experiment al group $(n=30)$ \\
\hline Age (years) - mean (SD) & $55.10(18.74)$ & $52.57(19.15)$ & $57.63(18.30)$ \\
\hline Education (years) - mean (SD) & $6.65(3.38)$ & $7.17(3.70)$ & $6.13(3.00)$ \\
\hline \multicolumn{4}{|l|}{ Sex $-n(\%)$} \\
\hline Men & $32(53.3)$ & $15(50.0)$ & $17(56.7)$ \\
\hline Women & $28(46.7)$ & $15(50.0)$ & $13(43.3)$ \\
\hline No. of cohabitants - mean (SD) & $2.77(1.18)$ & $2.67(1.12)$ & $2.87(1.25)$ \\
\hline \multicolumn{4}{|l|}{ Work status $-n(\%)$} \\
\hline Employed/Studding & $37(61.7)$ & $19(63.3)$ & $18(60.0)$ \\
\hline Unemployed/Homemaker/Retired & $23(38.3)$ & $11(36.7)$ & $12(40.0)$ \\
\hline \multicolumn{4}{|l|}{ Type of wound $-n(\%)$} \\
\hline Surgical wound & $17(28.3)$ & $10(33.3)$ & $7(23.3)$ \\
\hline Venous ulcer & $21(35.0)$ & $10(33.3)$ & $11(36.7)$ \\
\hline Arterial ulcer & $7(11.7)$ & $4(13.3)$ & $3(10.0)$ \\
\hline Ulcer of unknown etiology & $10(16.7)$ & $5(16.7)$ & $5(16.7)$ \\
\hline Diabetic wound & $5(8.3)$ & $1(3.3)$ & $4(13.3)$ \\
\hline \multicolumn{4}{|l|}{ No. of visits with this nurse $-n(\%)$} \\
\hline $0-10$ & $16(26.7)$ & $10(33.3)$ & $6(20.0)$ \\
\hline Oct-20 & $15(25.0)$ & $8(26.7)$ & $7(23.3)$ \\
\hline $20-30$ & $14(23.3)$ & $6(20.0)$ & $8(26.7)$ \\
\hline $30-40$ & $6(10.0)$ & $2(6.7)$ & $4(13.3)$ \\
\hline$>40$ & $9(15.0)$ & $4(13.3)$ & $5(16.7)$ \\
\hline \multicolumn{4}{|l|}{ Time with this nurse (years) $-n(\%)$} \\
\hline 2 years & $12(20.0)$ & $7(23.3)$ & $5(16.7)$ \\
\hline $2-4$ years & $19(31.7)$ & $12(40.0)$ & $7(23.3)$ \\
\hline $4-6$ years & $10(16.7)$ & $8(26.7)$ & $2(6.7)$ \\
\hline$>6$ years & $19(31.7)$ & $3(10.0)$ & $16(53.3)$ \\
\hline
\end{tabular}

allocated to the control group $(n=30)$ and to the experimental group $(n=30)$. In the first visit $\left(\mathrm{T}_{1}\right)$, all patients received the respective treatment from their family nurses. In the second visit $\left(\mathrm{T}_{2}\right)$, all patients received the appropriate treatment again, but the nurses in the experimental group put on a surgical mask. In a previous training session for the nurses (namely to ensure that the usual treatment procedures were maintained in all the appointments and regardless of the masks), the nurses were instructed to explain the reasons for using the mask if the patient asked. However, such a situation did not occur.

After each appointment, patients completed the Patient Satisfaction Questionnaire III (PSQ- III) [20] translated and cultural adapted to Portuguese in a separate room where comfort and privacy conditions were ensured. Consistent with the goals of the current study, patients were asked to rate their satisfaction regarding that particular visit with the family nurse. Nurses (and patients) responded to the question on how long they felt that the visit lasted also after each appointment.

\section{Instrument}

The PSQ-III assesses patient satisfaction about various domains of medical care, including aspects of the doctorpatient interaction and doctor's technical quality [20].

For the purposes ofassessing patientsatisfaction regarding relational aspects and the nurse's technical quality, five of the PSQ-III's original seven scales were translated and culturally adapted to Portuguese patients: General Satisfaction (all 6 items), Technical Quality (all 10 items), Interpersonal
Aspects (all 7 items), Communication (all 5 items), and Time Spent with the doctor (all 2 items). Each item is responded on a 1 to 5 Likert scale (1- strongly agree; 5- strongly disagree), with higher scores indicating greater satisfaction with the aspect of care named in the respective scale. Minimum and maximum scores for each scale are as follows: 6-30 (General Satisfaction), 10-50 (Technical Quality), 7-35 (Interpersonal Aspects), 5-25 (Communication), 8-40 (Financial Aspects), 2-10 (Time Spent with the doctor), and 560 (Access/ Availability/Convenience of care). The authors of the original PSQ-III added the scale on Time Spent with the doctor to this third generation of the questionnaire as an indicator of availability of resources [20], (not specifically as a measure of satisfaction with the doctor). The translation and cultural adaptation was thus conducted on 30 of the original PSQ-III's 51 items.

The questionnaire is self-administered (like the original PSQ-III), and patients in the current study took about 12 minutes to answer it.

\section{Analyses}

Statistical analyses were conducted in SPSS 24. Exposure was assessed through the differences in questionnaire responses between $T_{1}$ and $T_{2}$, and between control and experimental groups (Time*Group interaction effects). General Linear Model (GLM) Repeated Measures procedures were used to assess the effects of wearing the surgical mask on patients' satisfaction with the nurses' Technical Quality (9 items), Interpersonal Manner (7 items), Communication (5 items), General Satisfaction (6 items), and patients', as well 
as nurses' sensation of visit duration. Socio-demographic and clinical variables were included as covariates, and Bonferroni post hoc tests were conducted to correct for multiple comparisons.

In the analysis of socio-demographic and clinical covariates, patient education was not used because it showed a very high correlation with patient age $(\mathrm{r}=0.731$; $p=0.000$ ). Number of times that the patient and the nurse had met before was used, instead of how long this nurse is the patient's family nurse, because it provides a more realistic picture of actual patient-nurse interactions (the nurse might have been the family nurse of a patient for a long time without having seen the patient before).

\section{Results}

Cronbach's alpha coefficients for each scale at $\mathrm{T}_{1}$ (baseline data) in this sample were 0.75 (Interpersonal Aspects), 0.66 (Communication), 0.54 (Technical Quality scale), and 0.65 (General Satisfaction). The 60 patients who participated in the study were generally very satisfied with their family nurses regarding the PSQ-III aspects. Satisfaction levels were high in both the control and the experimental groups at $\mathrm{T}_{1}$ (Table 2). GLM Repeated Measure procedures showed no significant differences between the two groups regarding the four PSQ-III scales at $\mathrm{T}_{1}$ (group main effects were statistically non-significant, suggesting that the group alone did not account for differences in the PSQ-III aspects, and Bonferroni post hoc tests confirmed the nonsignificant differences between the two groups at $\mathrm{T}_{1}$ ). At $\mathrm{T}_{2}$, mean satisfaction levels dropped in the experimental group for all PSQ-III scales but remained equivalent to $\mathrm{T}_{1}$ in the control group.

A significant Time*Group interaction effect was observed for the four PSQ-III scales, indicating a highly significant effect of nurses wearing the surgical mask on patient's satisfaction (General satisfaction, $F(1)=18.695 ; p=0.000 ; \eta^{2}=0.244$; $O P=0.989$, Technical quality, $F(1)=25.132 ; p=0.000$; $\eta^{2}=0.302 ; O P=0.999$, Interpersonal aspects, $F(1)=15.484$; $p=0.000 ; \eta^{2}=0.211 ; O P=0.972$, and Communication, $\left.F(1)=22.106 ; p=0.000 ; \eta^{2}=0.276 ; O P=0.996\right)$.

\begin{tabular}{|c|c|c|c|c|c|c|}
\hline \multirow{5}{*}{ Table 2: Patient satisfaction in the PSQ-III scales: Means (standard deviations). } \\
\hline & $\begin{array}{c}\text { Control Group } \\
(\boldsymbol{n}=\mathbf{3 0})\end{array}$ & \multicolumn{1}{c|}{$\begin{array}{c}\text { Experimental } \\
\text { Group }(\boldsymbol{n}=\mathbf{3 0})\end{array}$} & $\begin{array}{c}\text { Total } \\
(\boldsymbol{n}=\mathbf{3 0})\end{array}$ \\
\hline & $\mathbf{T}_{\mathbf{1}}$ & $\mathbf{T}_{\mathbf{2}}$ & $\mathbf{T}_{\mathbf{1}}$ & $\mathbf{T}_{\mathbf{2}}$ & $\mathbf{T}_{\mathbf{1}}$ (baseline) \\
\hline General Satisfaction & 24.40 & 24.37 & 23.90 & 22.20 & 24.15 \\
\hline & $(3.61)$ & $(3.69)$ & $(2.28)$ & $(3.38)$ & $(3.01)$ \\
\hline Interpersonal Aspects & 30.27 & 30.40 & 31.13 & 29.37 & 30.70 \\
\hline & $(3.18)$ & $(3.09)$ & $(2.93)$ & $(3.83)$ & $(3.07)$ \\
\hline Communication & 21.10 & 21.13 & 21.63 & 19.90 & 21.37 \\
\hline & $(2.63)$ & $(2.65)$ & $(2.16)$ & $(2.58)$ & $(2.40)$ \\
\hline Technical Quality & 36.80 & 36.73 & 37.50 & 34.50 & 40.88 \\
\hline & $(3.74)$ & $(3.86)$ & $(3.32)$ & $(4.07)$ & $(3.51)$ \\
\hline
\end{tabular}

Bonferroni post hoc tests revealed statistically nonsignificant differences between $\mathrm{T}_{1}$ and $\mathrm{T}_{2}$ for each scale in the control group. However, the decrease from $\mathrm{T}_{1}$ to $\mathrm{T}_{2}$ in the experimental group was highly significant for all four scales (General Satisfaction, $F(1,58)=38.901 ; p=0.000 ; \eta^{2}=0.401$; $O P=1.000$, Technical quality, $F(1,58)=52.574 ; p=0.000$; $\eta^{2}=0.475 ; O P=1.000$, Interpersonal Aspects, $F(1,58)=$ 28.774; $p=0.000 ; \eta^{2}=0.316 ; O P=0.999$, and Communication, $\left.F(1,58)=42.560 ; p=0.000 ; \eta^{2}=0.423 ; O P=1.000\right)$. At $\mathrm{T}_{2}$, differences between control and experimental groups were significant for patients' General Satisfaction $(F(1,58)$ $\left.=5.627 ; p=0.021 ; \eta^{2}=0.088 ; O P=0.645\right)$ and satisfaction about nurses' Technical Quality $(F(1,58)=4.751 ; p=0.033$; $\left.\eta^{2}=0.076 ; O P=0.573\right)$. They were somewhat above the level of statistical significance for Communication $(F(1,58)$ $\left.=3.340 ; p=0.073 ; \eta^{2}=0.054 ; O P=0.436\right)$, and well above the level of statistical significance for Interpersonal Aspects $\left(F(1,58)=1.323 ; p=0.255 ; \eta^{2}=0.022 ; O P=0.205\right)$.

Inspection of possible influences of socio-demographic and clinical variables on changes associated with using the surgical mask revealed statistically non-significant effects of patients' age, sex, work status and number of co-habitants on the change from $\mathrm{T}_{1}$ to $\mathrm{T}_{2}$ in all four PSQ-III scales. The type of wound and the number of times that the patient met with the nurse before also did not affect the changes from $\mathrm{T}_{1}$ to $\mathrm{T}_{2}$ on all PSQ-III aspects.

Regarding the sensation of how long the visit lasted, few patients reported that the visit lasted more than 15 minutes at $\mathrm{T}_{1}$ ( 5 patients in the control group, and 8 patients in the experimental group). At $\mathrm{T}_{2}$, this number remained similar in the control group ( 6 patients), but more than doubled in the experimental group (17 out of 30 patients). Whereas patients' sensation of time agreed with effective visit duration in most cases at $\mathrm{T}_{1}$ (22 cases in the control group and another 22 in the experimental group), this number remained the same in the control group at $\mathrm{T}_{2}$ but decreased to nine cases in the experimental group. Twenty patients in the experimental group had the sensation that the visit lasted longer at $\mathrm{T}_{2}$ than it effectively did. Group main effects were statistically non-significant, indicating no effects of the group, per se, on sense of visit duration. However, the change from $\mathrm{T}_{1}$ to $\mathrm{T}_{2}$ was highly significant $\left(F(1)=33.126 ; p=0.000 ; \eta^{2}=0.364\right.$; $O P=1.000)$, and so was the Time*Group interaction $(F(1)=$ $\left.25.791 ; p=0.000 ; \eta^{2}=0.308 ; O P=0.999\right)$. This indicates that nurses wearing the masks produced a sense of longer visit duration among patients.

Similar results were found for the nurses. At $T_{1}$, few nurses reported that the visit lasted longer than 15 minutes (in 9 cases out of 30 in the control group, and in 8 cases out of 30 in the experimental group). At $\mathrm{T}_{2}$ this number remained similar in the control group (7 cases out of 30) but more than doubled in the experimental group (17 cases out of 30). Like with patients, nurses' sensation of time agreed with actual 
visit duration in most cases at $\mathrm{T}_{1}$ (20 cases in the control group and 24 cases in the experimental group). This number remained the same in the control group at $\mathrm{T}_{2}$ but decreased to 11 cases in the experimental group. Nineteen nurses in the experimental group had the sensation that the visit lasted longer at $\mathrm{T}_{2}$ than it effectively did. Group main effects were again statistically non-significant, but the changes from $\mathrm{T}_{1}$ to $\mathrm{T}_{2}$ were significant $\left(F(1)=7.228 ; p=0.009 ; \eta^{2}=0.111\right.$; $O P=0.753$ ), and the Time*Group interaction was highly significant $\left(F(1)=15.080 ; p=0.000 ; \eta^{2}=0.206 ; O P=0.968\right)$. This shows an effect of wearing the mask on nurses' sense of stretched visit time.

Effects of patients' socio-demographic characteristics on the change from $T_{1}$ to $T_{2}$ in the sensation of visit duration were all non-significant for both patients and nurses. Effects of clinical variables were also non-significant for patients. For nurses, however, both clinical variables (type of wound and number of times that the nurse met with the patient) had a significant impact on the change from $T_{1}$ to $T_{2}$ in nurses' sensation of how long the visit lasted. Specifically, nurses wearing their masks felt that the visit became longer especially for patients with varicose ulcers and complications of surgical wounds $\left(F(1)=11.495 ; p=0.001 ; \eta^{2}=0.170\right.$; $O P=0.915)$. They additionally sensed that the visit became longer for those patients whom they met more frequently, $F(1)=4.308 ; p=0.043 ; \eta^{2}=0.071 ; O P=0.532$. The type of wound was unrelated with the number of times that the nurse had been with the patient.

\section{Discussion}

Research has shown that the use of the surgical mask influences communication between patients and health professionals. The aim of this study was to evaluate the extent to which wearing the mask in primary health care has an impact on an already existing relationship between nurse and patient. Our results indicate that wearing the surgical mask affects patients' satisfaction with the nurses' interpersonal manner, communication, and technical quality, also affecting patients' general satisfaction with the encounter. In all these cases, the impact of the mask was negative. In addition, both patients and nurses had the sensation that the appointment took significantly longer when the nurse wore the mask than when the nurse did not wear the mask. This study is in line with previous research showing a negative effect of wearing the surgical mask on satisfaction among patients who already had a relationship with their health professionals [14].

For nurses, the observed significant effects of the clinical variables on perception of visit duration suggests greater discomfort, during mask-wearing treatments, with particular types of wounds (or wound-suffering patients) and with patients whom nurses had met more often. The results for patients did not match these findings. For patients, no sociodemographic or clinical variables influenced the effect of the mask on either satisfaction or sensation of visit duration.
Despite the decrease in patient satisfaction when nurses put on their facemasks, satisfaction levels were still high. It is possible that the prolonged contacts with the family nurses have attenuated the impact of the mask on patients' perceptions of the relationship, namely by increasing their tolerance to this situation. The impact might be stronger when a previous nurse-patient relationship does not exist.

This study focused on a novel figure in primary care in Portugal, the family nurse, which started to exist in 2008 but has only been officially recognized more recently, in 2014. Our results suggest that the family nurse constitutes an excellent vehicle to the establishment of satisfactory clinical relationships, with value to the patients.

\section{Limitations}

Future studies can include family nurses and other nurses in primary care for comparison. Future studies can compare the impact of widespread measures of mask use on the population after the pandemic situation of COVID-19. More studies are also necessary to investigate the effects of using the mask in other nursing settings, namely where prolonged contacts between nurse and patient do not exist. Research focusing on the role of habituation to the use of the mask, and on the effects of possible explanations offered to patients about the reasons for wearing the mask are also important. Nurses may need to use the surgical mask in their daily practice, and research is necessary to investigate ways of mitigating the negative effects that wearing it have on patients. This study showed that not only were aspects of the relationship negatively affected, but satisfaction with the nurse's technical quality also did not increase when they put on their surgical masks, quite the contrary.

\section{Conclusion}

When a previous relationship exists, nurses wearing the surgical mask in primary care in Portugal negatively affects patient satisfaction with both the patientnurse relation and the nurses' technical quality. The impact of the mask occurs not only for patients but also for nurses' sensation of visit duration.

\section{Implications for practitioners}

This study provides a scientific basis for the use of the mask beyond the individual criteria and the experiential and intuitive logic that often underlie decisions to wear it. Awareness to the effects of wearing the mask on the patient-nurse relation can help nurses decide how to manage encounters in which they might use this protective device without jeopardizing the quality of the relationship.

\section{References}

1. Grupo Regional de Controlo de Infeção. Manual de controlo de infeção. Porto: ARSNorte Portugal. 2013. 
2. NevesHCC, SouzaACS. Segurança dos trabalhadores de enfermagem e fatores determinantes para adesão aos equipamentos de proteção individual. Revista Latino-Americana de Enfermagem. 2011. http://www.redalyc.org/articulo.oa?id=281421955018

3. Mafra, Denise Aparecida Lopes. Perceção dos enfermeiros sobre a importância do uso dos equipamentos de proteção individual para riscos biológicos em um serviço de atendimento móvel de urgência. O Mundo da Saúde São Paulo. 2008; 32: 31-38.

4. Atcherson SR, Mendel LL, Baltimore WJ, Patro C, Lee S, et al. The effect of conventional and transparent surgical masks on speech understanding in individuals with and without hearing loss. J Am Acad Audiol. 2017; 28: 58-67.

PubMed: https://pubmed.ncbi.nlm.nih.gov/28054912/

5. Shakya KM, Noyes A, Kallin R, Peltier RE. Evaluating the efficacy of cloth facemasks in reducing particulate matter exposure. J Expo Sci Environ Epidemiol. 2017; 27: 352-357.

PubMed: https://pubmed.ncbi.nIm.nih.gov/27531371/

6. Mendel LL, Gardino JA, Atcherson SR. Speech understanding using surgical masks: A Problem in Health Care? J Am Acad Audiol. 2008; 19: 686-695.

PubMed: https://pubmed.ncbi.nlm.nih.gov/19418708/

7. Firth-Cozens J. Why communication fails in the operating room. Quality \& Safety in Health Care. 2004; 13: 327.

PubMed: https://www.ncbi.nlm.nih.gov/pmc/articles/PMC1743895/

8. Kahriman I, Nural N, Arslan U, Topbas M, Can G, et al. The effect of empathy training on the empathic skills of nurses. Iran Red Crescent Med J. 2016; 18: e24847.

PubMed: https://pubmed.ncbi.nlm.nih.gov/27621922/

9. Macdonald LM. Expertise in everyday nurse-patient conversations: The importance of small talk. Global Qual Nurs Res. 2016; 3: 2333393616643201.

PubMed: https://pubmed.ncbi.nlm.nih.gov/28462336/

10. Bikker AP, Fitzpatrick B, Murphy D, Mercer SW. Measuring empathic, person-centred communication in primary care nurses: validity and reliability of the Consultation and Relational Empathy (CARE) Measure. BMC Fam Pract. 2015; 16: 149.

PubMed: https://pubmed.ncbi.nlm.nih.gov/26493072/

11. Lee M, Yom YH. A comparative study of patients and nurses perceptions of the quality of nurses services, satisfaction and intent to revisit the hospital: A questionnaire survey. Int J Nurs Stud. 2007; 44: 545-555. PubMed: https://pubmed.ncbi.nlm.nih.gov/16687147/

12. Marques Lopes SMG. Satisfação dos utentes com os cuidados de enfermagem na Unidade de Cuidados de Saúde Personalizados de Eiras. (Master's thesis). Superior Nursing School of Coimbra. 2013.
13. Thornton RD, Nurse N, Snavely L, Hackett-Zahler S, Frank K, et al. Influences on patient satisfaction in healthcare centers: a semiquantitative study over 5 years. BMC Health Serv Res. 2017; 17: 361. PubMed: https://pubmed.ncbi.nlm.nih.gov/28526039/

14. Wong CK, Yip BH, Mercer S, Griffiths S, Kung K, et al. Effect of facemasks on empathy and relational continuity: a randomised controlled trial in primary care. BMC Fam Pract. 2013; 14: 200. PubMed: https://pubmed.ncbi.nlm.nih.gov/24364989/

15. Ramos N. Interculturalidade e comunicação nos cuidados de saúde. In Ramos, N. (eds.). Saúde, Migração e Interculturalidade: Perspectivas Teóricas e Práticas. João Pessoa: Editora Universitária/UFPB. 2008.

16. Epstein RM, Hundert EM. Defining and assessing professional competence. JAMA. 2002; 287: 226-235. PubMed: https://pubmed.ncbi.nlm.nih.gov/11779266/

17. Ware JE, Jr., Snyder MK, Wright WR, Davies AR. Defining and measuring patient satisfaction with medical care. Eval Program Plann. 1983; 6: 247-263.

PubMed: https://pubmed.ncbi.nlm.nih.gov/10267253/

18. Duffy FD, Gordon GH, Whelan G, Cole-Kelly K, Frankel R, et al. Assessing competence in communication and interpersonal skills: the Kalamazoo II report. Acad Med. 2004; 79: 495-507. PubMed: https://pubmed.ncbi.nIm.nih.gov/15165967/

19. Chang JT, Hays RD, Shekelle PG, MacLean $\mathrm{CH}$, Solomon DH, et al. Patients' global ratings of their health care are not associated with the technical quality of their care. Ann Int Med. 2006; 144: 665-672. PubMed: https://pubmed.ncbi.nlm.nih.gov/16670136/

20. Hays RD. Davies AR, Ware JE. Scoring the Medical Outcomes Study Patient Satisfaction Questionnaire: PSQ-III. 1987:

https://www.rand.org/content/dam/rand/www/external/health/ surveys_tools/psq/psq3_s coring.pdf

21. Ware JE, Snyder MK, Wright WR. Development and Validation of Scales to Measure Patient Satisfaction with Medical Care Services. 1976A; I: Part A:

22. Review of Literature, Overview of Methods, and Results Regarding Construction of Scales. (NTIS Publ. No. PB 288-329) Springfield, VA, National Technical Information Service.

23. Ware JE, Snyder, Wright WR. Development and Validation of Scales to Measure Patient Satisfaction with Medical Care Services. Part B: Results Regarding Scales Constructed from the Patient Satisfaction Questionnaire and Measure of Other Health Care Perceptions. (NTIS Publ. No. PB 288-330) Springfield, VA, National Technical Information Service. 1976b. 